\title{
Advanced Control of Switching Ignition by Smart Helmet
}

\author{
Seelam Vasavi Sai Viswanada Prabhu Deva Kumar \\ ITM University, Gwalior (MP), India \\ Email: betn1ec14023_vasavi@itmuniversity.ac.in \\ Shyam Akashe \\ ITM University, Gwalior (MP), India \\ Email: shyam.akashe@itmuniversity.ac.in \\ Vikram Kumar \\ ITM University, Gwalior (MP), India \\ Email: kumarvikram811@gmail.com
}

Received: 18 September 2017; Accepted: 07 November 2017; Published: 08 February 2018

\begin{abstract}
The impact of Accident effect, a lot of human livelihoods and their career, due to the negligence of wearing the helmets on a daily basis in India. To end this suffering, we have a social responsibility development projects. The motorcycle driver without wearing the helmet can be killed if it hit or crash and bring his life in danger. Wearing a helmet reduces the possibility of danger of life. In India, for example, wearing a helmet is mandatory in the law and the drivers need to follow it. Similar rules are in many countries. Therefore, this project is designed to improve motorcycle safety and make motorcyclist compulsory for wearing it. As you can see, we have a lot to think about it. It is a type that is used in the driver's helmet to drive a bike safely. The aim of this paper is to protect the driver life and decrease the death rate at road accident by making the helmet. It uses a hands-free kit and advances feature like compulsory of wearing helmet and theft security. Bluetooth wireless communication module $(2.4 \mathrm{GHz}$ band transceiver) can be used for transmission between the transmitter and the receiver. The driver needs to wear a helmet otherwise a helmet automatically keeps the engine OFF. If rider wears the helmet, ignition will be automatically ON. In the sensor, we transmit information to the wireless communication module, which is connected to the bike. This system is one of the devices built in the helmet; the second devices are inside the bike. Monitor recognizes the power devices with a Force-sensing resistor (FSR). Wireless data receiver, encoder, and a transmitter are used to communicate helmet with the bike. AT mega controller in both devices used as a CPU. It is one of the most advanced electronic projects for the Road Safety Systems.
\end{abstract}

Index Terms - Driver Safety, Smart Helmet, Atmega Controllers, Force sensing resistor (FSR), Embedded C, USART Communication, 7805IC.
Tools-CodeVisionAVR, PCB Wizard

Programmer-USBasp

\section{INTRODUCTION}

Road accident had become one of the major topics of discussion for the whole world. After repeated awareness campaign organized by government authority regarding the importance of helmet for road safety, peoples are paying no heed to it. Most motorcyclists' death is due to head injuries. In India, 78\% of road vehicles are twowheelers. $29 \%$ of total road accidents are of two-wheelers. It is statistically increasing from $26.3 \%$ in 2013 to $27.3 \%$ in 2014 and $28.8 \%$ in 2015 . So, it has become one of the most secure modes of transport nowadays. The UN study tells, "Motorcyclists are 26 times more likely to die in a road crash than drivers of passenger cars". Wearing a proper helmet improves their probability of endurance by $42 \%$ and helps to avoid $69 \%$ of injuries to riders.

A motorcyclist's helmet, also called safety helmet, acts as a protective headgear because it prevents from any fatal head injury. So, every government has some laws to enforce it to their city for making it compulsory to wear. In India, the Sections 128 and 129 of the Motor Vehicles (MV) Act, 1988, made the wearing of helmets by twowheeler users mandatory.

The main objective of this project is to make motorcyclist user wear the helmet. Either way, it is necessary to wear it, too on the ignition of the engine. In case, if the driver is not in a position to wear the helmet then the driver doesn't have a right to drive the vehicle. This will also keep the vehicle secure from any theft. The helmet which we have proposed is made from the combination of Transmitter and the Receiver section. The Transmitter portion is embedded with a sensor, Bluetooth module and controller. The Receiver portion is embedded 
with Bluetooth module, controller, status display and relay. The Controller is used in this project to control the whole operation. The ignition of the motorcycle can start only if the users wear the helmet properly.

\section{8-BIT MICROCONTROLLER}

In this project, we use two controllers ATMEGA16L and ATMEGA8A is an 8-bit microcontroller designed to support low power CMOS technology for better structural design RISC AVR $32 * 8$ High-Performance Registry Features. Manufactured by Atmel with Drive Unit Nonvolatile storage is very compact. The on-chip system memory 16 KB Flash memory program EEPROM 512 $\mathrm{Kb}$ and $1 \mathrm{~Kb}$ SRAM internal memory. This ATMEGA16L microcontroller has a 40-pin, programmable 32-pin line input (4 ports each port 8) and ATMEGA8A has 28 pin, 24-pin programmable input lines (3 ports per PIN of port 8) has pulse modulation Four channels, eight ADC channels with 10-bit input terminal 3 are used for DC (5V), two pins are used for the 3-pin AREF, AVCC and RESET crystal oscillator (XTAL2, XTAL1). This microcontroller operates at $2.7 \mathrm{~V}$ - $5.5 \mathrm{~V}$ from the $0.35 \mathrm{~mA}-1.1 \mathrm{~mA}$ power in idle mode with the $0-8 \mathrm{MHz}$ level. Boot loader software continues to work while the flash is updated application area to read correctly during the registration. The combination of 8 bits of automatic flash chip system processor RISC programmable monolithic machines. These are most commonly used microcontroller is a convenient and easy to implement the integrated application. It supports Embedded $\mathrm{C}$ and Assembler language of the coding system.

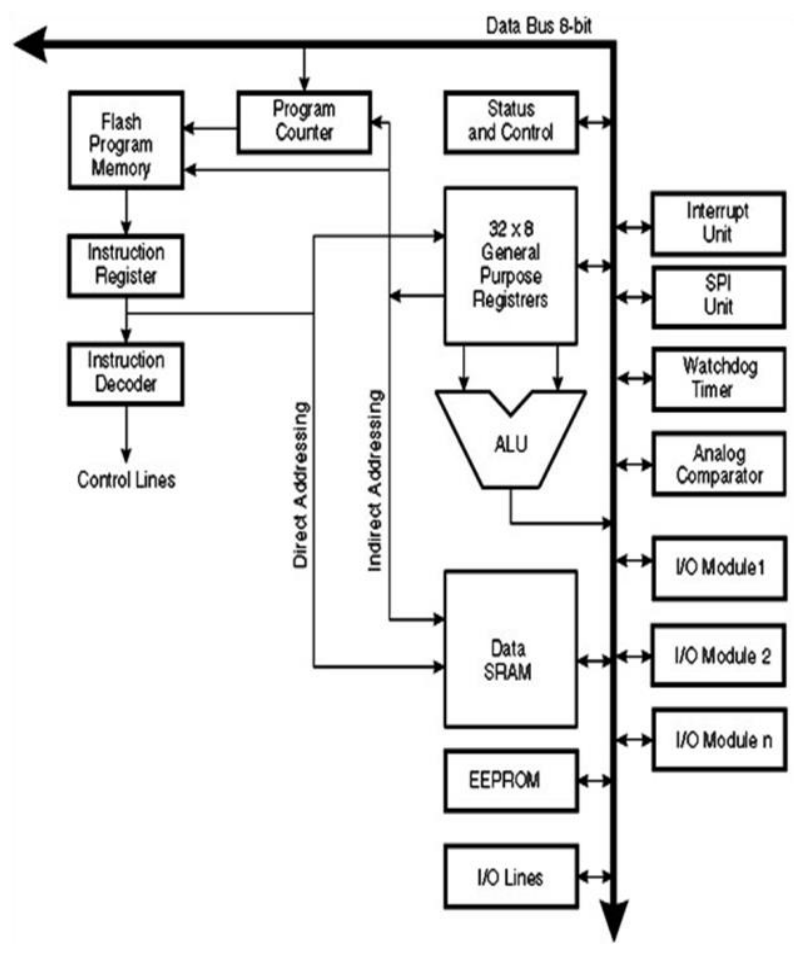

Fig.1.General Architecture of ATMEL microcontroller

\section{Bluetooth Module}

HC-05 Bluetooth module is an easy-to-use (SPP) Serial Port Protocol module. It is considered for transparent wireless serial communication. HC-05 Bluetooth module can be used in master or slave configurations, building it an excellent resolution for wireless communication. Bluetooth V2.0 + EDR 3Mbps is complete Advanced Data Bluetooth Rate $2.4 \mathrm{GHz}$ module and total bandwidth. The CSR Blue Core Bluetooth 04 uses the system with a single external CMOS chip technology, and (Depending on the adaptive frequency jumper frequency) $\mathrm{AFH}$.

Bluetooth module HC-05 is a master/slave drive. By default, the module is set in SLAVE mode. Function modules (master or slave) can only configure AT commands. Slave units cannot establish a connection with an additional device, Bluetooth, but it can recognize associates connections. The master module can start a connection to other devices. You can only use it for a serial port replacement to establish a connection between MCUs and GPS, PCs to the implementation project, etc.

\section{Hardware features:}

- Typical $-80 \mathrm{dBm}$ sensitivity.

- Power transmission at up to $+4 \mathrm{dBm}$.

- Input/output voltage is 3.3-5volts.

- IOP control (programmable input / output).

- UART interface with programmable baud rate.

- Built-in antenna included.

Software features:

- $\quad$ Standard slave transmission speed: 9600, 8 data bits, 01 stop bits, no parity.

- Power turns on automatically by default and connects to the last device.

- $\quad$ Pairing allow you to connect standard devices.

- $\quad$ PIN code auto sync: "1234", by default.

\section{(A) Enable:}

If the enable is low, means that the module that it is not communicating with the device is not turned off. While the enable is opened, or when connected to $3.3 \mathrm{~V}$, it is activated, the module enters, it remains in communication.

(B) $V c c$ :

Voltage source is $+3.3 \mathrm{~V}$ to $+5 \mathrm{~V}$

(C) GND:

Voltage source is $-3.3 \mathrm{~V}$ to $-5 \mathrm{~V}$

(D) Txd and Rxd:

These two pins, acts as an interface of UART communication

(E) State:

It acts as a status indicator. Modules, other devices, though not in combination with a low-level signal. The low state indicates that the LED flash continuously, the module is not connected to another device. To another 
device, signal active state High. At, LED indicates that the device is configured to flash over a fixed delay $2 \mathrm{c}$ in the delay example.

\section{(F) Button Switch:}

It is used to change the module in the AT command mode. , To start the power button to run second. With using the AT command mode, a user can modify the parameters of this module, only when BT device is not paired with other. When connected to all Bluetooth devices, and to start communication with the device, does not work with the AT command mode.
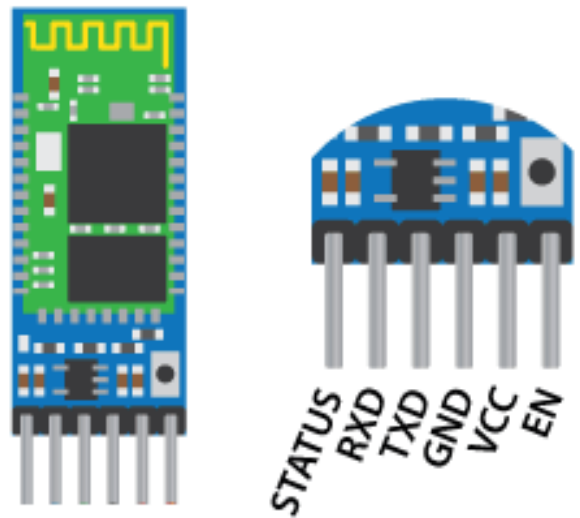

Fig.2. Bluetooth Module

\section{ForCE SENSING RESISTOR (FSR)}

It is a force sensitive resistor with a square detection surface of $1.75 \times 1.5^{\prime \prime}$, which varies the resistance to the pressure that is exerted on the detection zone. FSR is basically a resistance that changes the resistance value (in ohms); depending on how much the pressure resistance applies. The FSR will be $1 \mathrm{M} \Omega$ higher resistance. FSRs can be anywhere in the range of $100 \mathrm{~g}$ to $10 \mathrm{~kg}$. These sensors are easy to install and are ideal for pressure measurement, but they are not very accurate. Use it to detect if it is pressed, but you cannot decide to use it as a staircase.

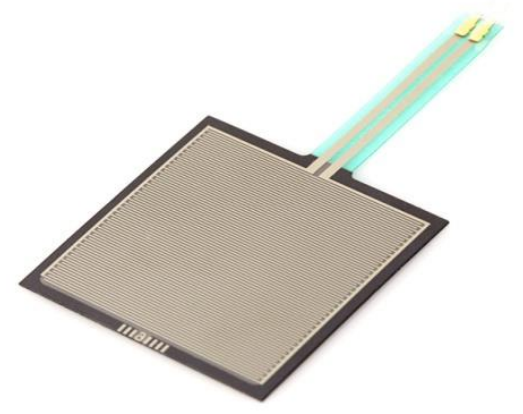

Fig.3. Force Sensing Resistor
FSR features (Force Sensing Resistor) has the following drawback that are linear. The following table is a logarithmic curve. And it is not a linear feature.

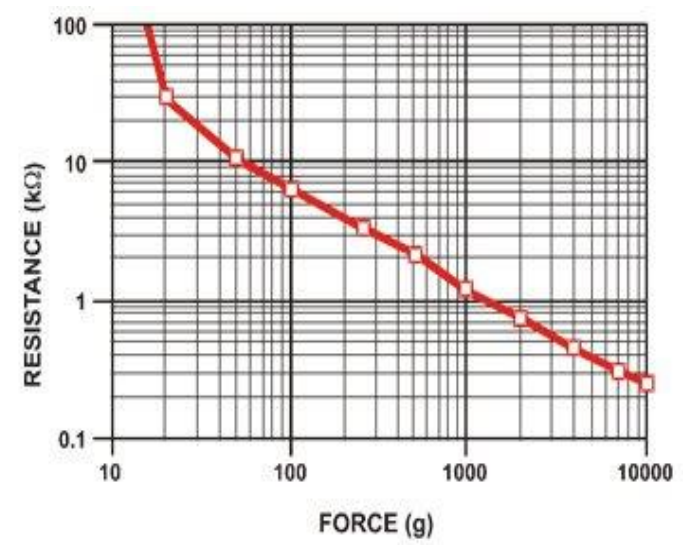

Fig.4. Force Vs Resistance

The following graph of force and conductance,

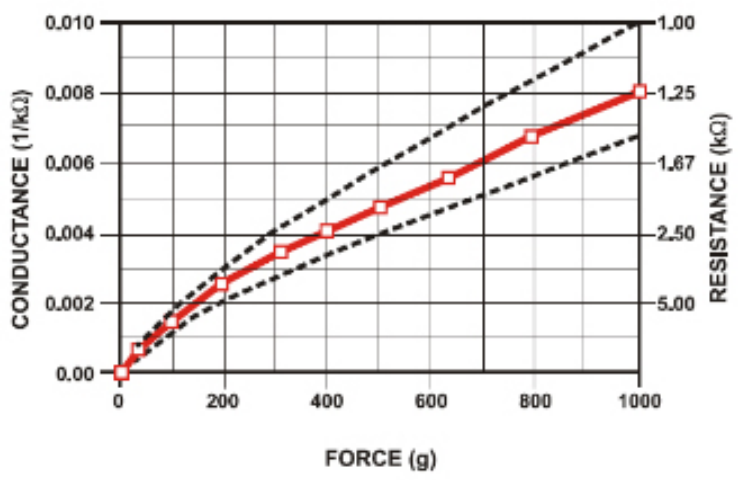

Fig.5. Conductance Vs Force $(0-1 \mathrm{Kg})$ Low Force Range

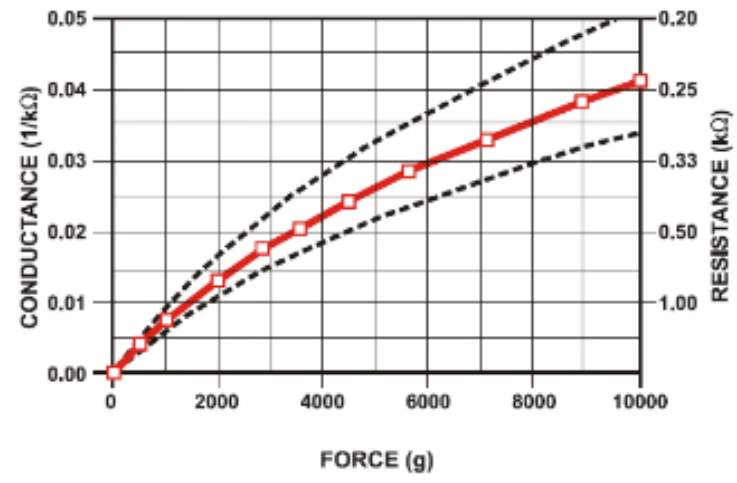

Fig.6. Conductance Vs Force(0-10Kg)

$\mathrm{G}=$ Conductance

$\mathrm{F}=$ Force

$\mathrm{A}=$ Maximum conductance

$\mathrm{B}=$ The force with which the maximum conductance is half the maximum conductance.

Equation (1):-

$$
G=\frac{a F}{(b+F)}
$$




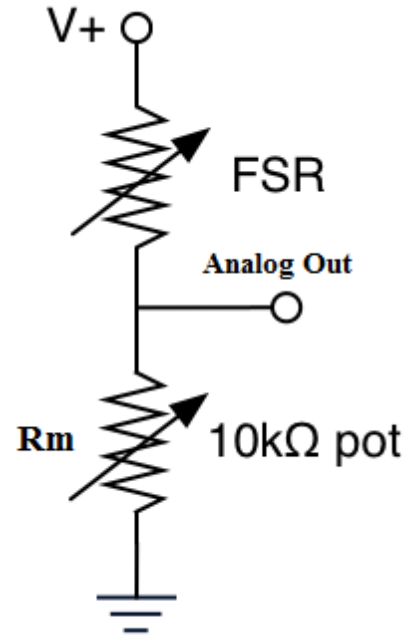

Fig.7. Voltage Divider

The voltage divider between output voltage and input voltage can be expressed by the Equation(2):-

$$
V o=\frac{R m V i}{R m+R}
$$

$\mathrm{Vi}$ is the input voltage, Vo is the output voltage, $\mathrm{Rm}$ is the resistor connected in series with the FSR, and $\mathrm{R}=1$ / G.

Input voltage is $\mathrm{Vi}$, Output voltage is Vo, Seriesconnected resistance with the FSR is $\mathrm{Rm}$, and $\mathrm{R}=1$ / G.

From Equation(2)

$$
V o=\frac{a R m V i F}{F(a R m+1)+b}
$$

If,

$$
F \ll \frac{b}{(a R m+1)}
$$

It is linear.

Table.1.

\begin{tabular}{|l|l|l|c|c|c|}
\hline $\begin{array}{l}\text { Force } \\
(\mathrm{lb})\end{array}$ & $\begin{array}{l}\text { Force } \\
(\mathrm{N})\end{array}$ & $\begin{array}{l}\text { FSR } \\
\text { Resistance }\end{array}$ & $\begin{array}{c}\text { (FSR + R) } \\
\Omega\end{array}$ & $\begin{array}{l}\text { Current thru } \\
\text { FSR+R }\end{array}$ & $\begin{array}{c}\text { Voltage } \\
\text { across } \mathrm{R}\end{array}$ \\
\hline None & None & Infinite & Infinite! & $0 \mathrm{~mA}$ & OV \\
\hline $\mathbf{0 . 0 4} \mathrm{lb}$ & $\mathbf{0 . 2 \mathrm { N }}$ & $30 \mathrm{~K} \Omega$ & $40 \mathrm{~K} \Omega$ & $0.13 \mathrm{~mA}$ & $1.3 \mathrm{~V}$ \\
\hline $\mathbf{0 . 2 2} \mathrm{lb}$ & $1 \mathrm{~N}$ & $6 \mathrm{~K} \Omega$ & $16 \mathrm{~K} \Omega$ & $0.31 \mathrm{~mA}$ & $3.1 \mathrm{~V}$ \\
\hline $\mathbf{2 . 2} \mathrm{lb}$ & $10 \mathrm{~N}$ & $1 \mathrm{~K} \Omega$ & $11 \mathrm{~K} \Omega$ & $0.45 \mathrm{~mA}$ & $4.5 \mathrm{~V}$ \\
\hline $\mathbf{2 2} \mathrm{lb}$ & $100 \mathrm{~N}$ & $250 \Omega$ & $10.25 \mathrm{~K} \Omega$ & $0.49 \mathrm{~mA}$ & $4.9 \mathrm{~V}$ \\
\hline
\end{tabular}

\section{USART COMMUNICATION}

In synchronous mode, data and clock are necessary; data is transmitted at a constant rate and data is typically transmitted, one byte at a time.
In asynchronous mode, only data is required, the data does not need to be transmitted at a constant speed and data is typically sent as a block. It allows more DTR (data transfer rate) if you keep all other factors constant.

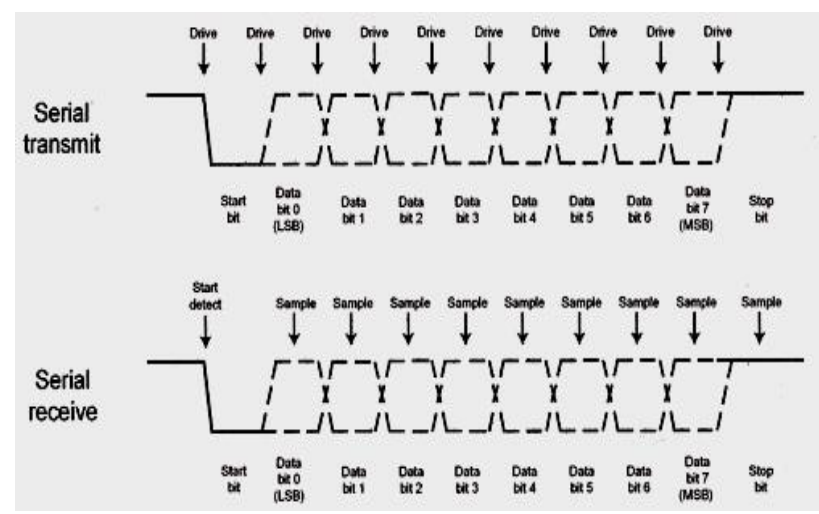

Fig.8. waveform design of data transmitter and receiver.

\section{EMBEDDED C}

During the years of microprocessor-based systems, we are developing programs for using counters and taking EPROM. There was no mechanism to find the program executed. They demonstrated the effectiveness of the program, such as LEDs and switches. They are very expensive and not very consistent but have fewer developers, a circuit emulator (ICE). At the same time, the use of a set of the processing system of language program was to reduce integrated movement with arbitrary compact embedded $\mathrm{C}$ language. $\mathrm{C}$ programming language is the most widely used processor/controller integrated. Arrays are also used, in particular, however, to implement parts of the code, such as efficiency of synchronization code extension, but they are very important.

Assembler programs were not useful between structures because they are explicit to the assembly language of the processor. To circumvent this problem, a number of high-level languages, including $C$, have appeared. Other languages like other arrivals such as PLM, Modula-2, and Pascal are not widely accepted. Of this, $\mathrm{C}$ won extensive recognition, not only for embedded systems but also for office applications. Although $\mathrm{C}$ has lost its radiance as a major language for universal applications, it has a physically strong built-in encoding. Built-in $\mathrm{C}$ classification for high recognition, such as cross compiler and compiler, like ice, etc. I found various tools all of which are doing the development of embedded systems more easily $\mathrm{C}$ and assembler language there are more systems that integrated programming is a natural choice. The use of assembly language, however, was developed with limited effectiveness in terms of code size and speed. Also, assembly code is not a growth requiring a high cost of convenient software code to grow. The development of small code is not very difficult. Programs such as important/tasks are increasingly complex to handle in assembly language. Construction of 
high-quality developers should also be complicated. Therefore, in advanced languages, it is chosen for programming of embedded systems. Constructed $\mathrm{C}$, for example, uses the most of the syntax and semantics of the C standard (case, switch) conditional function) main (), variable definition, data type, array, and string declaration, integer bit operation

Note:

1. Assembly language comparison was written in $\mathrm{C}$ code, more affordable and scalable, more consistent for all platforms.

2. The $\mathbf{C}$ compiler is currently in practical use for $\mathbf{C}$ integrated campaign and now many experienced programmers

\section{USBASB PROGRAMMER}

USBasp is an integrated USB controller based on Atmel AVR control circuit. It consists of single or ATmega8 ATmega88 and passive part pair. The programmer is using the only USB firmware driver. No special USB driver is required. You need to install to Windows USBASP driver, use this programmer. There is a possibility that the USB power supply is actually too small and the possibility that the large capacity USB drive will be damaged may be too small. With the general $100 \mathrm{~mA}$, more cards need to be equipped with separate sources. By operating the bridge figure 8 , developers can set different power options. The program needs to allow the programmer to support and talk for software and chip purposes. To do this, you can perform software support reading (read or AVR flash backup). If the operation succeeds, it means that it can communicate with the software supported by the programmer and connect to the target board. If that fails you need to find the cause. The controller will operate more stable if the bridge "slow clock" $(<1.5$ megahertz) is shorted. Oscilloscope programming 062 (06201 P, $06201 \mathrm{KP}$ or $06202 \mathrm{KP})$ is used. Pin head is compatible with time oscilloscope link.

However, in order to load the program (HEX file) of the microcontroller equipped with the USBASP programmer, appropriate software is necessary. Fortunately, an open free program for downloading, downloading and manipulating is combined with flash, EEPROM and microcontroller AVR programmer code. This is part of the software package. You can easily install Sinaprog or extreme burner, which has a number of Atmel AVR open source software development tools.

\section{7805 VOLTAGE REGULTOR IC}

78XX (sometimes L78xx, LM78xx, MC78xx ...) is a family of linear integrated circuit autonomous fixed voltage regulators. The $78 \mathrm{XX}$ family is used for electronic circuits that require a regulated power supply for general use and low cost ease. The family the IC family $78 X X$ (with 12 volt 7812 , e.g. 7805 has 5 volt output), 2 digit output voltage is exchanged. It is a $78 \mathrm{XX}$ line positive voltage regulator: it generates a positive voltage relative to the common base. Supplemental negative voltage regulator is 79xx related equipment line. It can be used in combination to provide positive and negative voltage to the same power supply circuit as 78XX. The 78XX integrated circuit has a general setting, $7808(8 \mathrm{~V}) 7809(9 \mathrm{~V}) 7810(10 \mathrm{~V}) 7812$ (12 V) 7815 (15 V) $7818(18 \mathrm{~V})$ and 78247805 (5 V), $7806(6 \mathrm{~V})(24 \mathrm{~V})$. 7805 is the most common because its stable 5 volt power supply provides the most power for the TTL component most. It is less common in the so powerful version like the LM78 LMxx series (500 mA) and the LM78L xx (100 mA) from the National Semiconductor series. Some devices provide slightly different voltages, as usual, as are the LM78L62 (6.2 volts), LM78L82 (8.2 volts) and ST Microelectronics L78L33ACZ (3.3 volts).

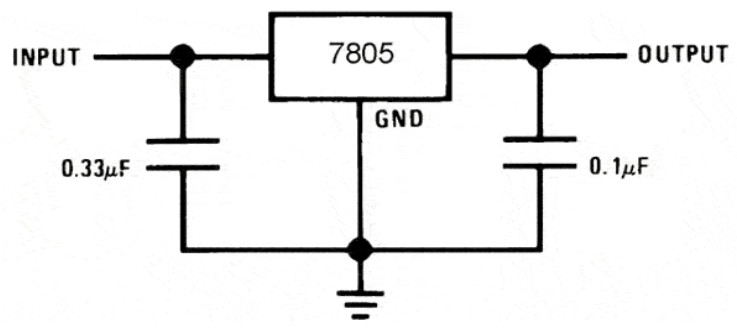

Fig.9. Schematic of Voltage Divider.

\section{SYSTEM SETUP}

In this research work we need configure and setup a system by this following below five steps:

\section{(A) Configure and Pair of two Bluetooth module}

We need to configure both modules. To do this, we need to switch to AT command mode, where we are how to do that. First, you need to connect the wiring diagram of the RS232 TTL, Bluetooth module. We need to connect the RS232 TTL pins to the HC-05 Bluetooth module pins as shown in fig. 11 .

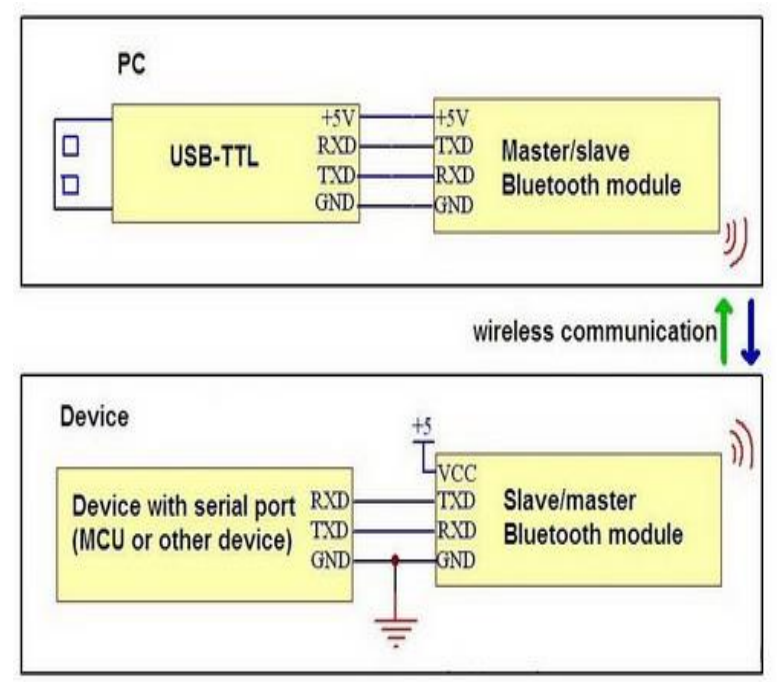

Fig.10. Configuration of the Bluetooth modules. 
Therefore, the RX pin of RS232 must be connected to the Bluetooth module TXD pin, and vice-versa. Now the Bluetooth module enters the command mode you need to take a small button on the terminal to provide the module. The Bluetooth module flashes, LEDs every 2 seconds, which means that we entered correctly in AT command mode. Make sure that connection of RX and TX lines should be proper. So we need to run a PUTTY tool to serial monitor and choose "both NL and CR" and the "38400 baud" rate is not the default baud rate of the Bluetooth module. Then it is ready to send commands and their formats. All commands start with "AT" ending with "?" When followed by "parameter name" followed by "+". When we enter the new value of this parameter, we return the value of the current parameter or, the "=" sign.

\section{(B) Configuring Slave Bluetooth module}

Confirm the need to return the message to "OK" when you enter "AT" command. So, when we get in, "AT+UART?" We need to get back to the sequence showing the default baud rate 38400, "ROLE=0" Which means that the Bluetooth device which is messaging is in the slave mode. "AT+ADDR?" which means that the Bluetooth device is finding the address: $\mathrm{XXXX}$ : $\mathrm{XX}$ : $\mathrm{XX}$ : XX.

This address is requiring the master configuration. In fact, when in the slave configuration of the address is everything we need, and we will change many of the various parameters such as name, transmission speed, password etc.,

\section{(C) Configuring Master Bluetooth module}

Set up another Bluetooth module as the master device. First, and to ensure that it is the same as the input slave device 38400 , check the baud rate and "AT+ROLE $=1$ " set the Bluetooth module as the master device. After using "AT+CMODE=0", establish the command "AT+ $\mathrm{BIND}=\mathrm{XXXX}, \mathrm{XX}, \mathrm{XX}, \mathrm{XX}$ " connection "constant direction mode" command to set the address of the previously marked slave device.

When we write the address we need to use a comma instead of two points. Also, we woke up a master to connect to any device within its transmission range and the step before the command ' 0 ' introduced ' 1 ' instead of 'AT+CMODE' skipped although it may be.

However, this is necessary for the basic configuration of the Bluetooth module to re-activate modules within seconds that the master connects to the slave, currently acting as the master and slave devices, connecting the normal data It's all. Both modules are flashing every 2 seconds, indicating a successful connection.

\section{(D) Installing the designed circuit board in the helmet}

The circuitry installed in a helmet is Transmitter circuit designed by an atmega 8 microcontroller with the internal supply of $5 \mathrm{~V}$ given by a $7805 \mathrm{IC}$ through battery. In this device we used Force Resistive Sensor (FSR) which is used to receive the analog output according to the applied force. These analog data will read by using analog to digital converter (ADC) pin of microcontroller. The value will read according to the reference voltage (Vreff). Master Bluetooth module is as a transmitter which transmits the data received from the microcontroller. Bluetooth module is communicated with USART pins of the microcontroller. Logic given in the program is that, the analog voltage is greater the reference voltage then usart transmits the data from master to slave. Finally, the whole module is implemented in the helmet as shown in figure. 12 .

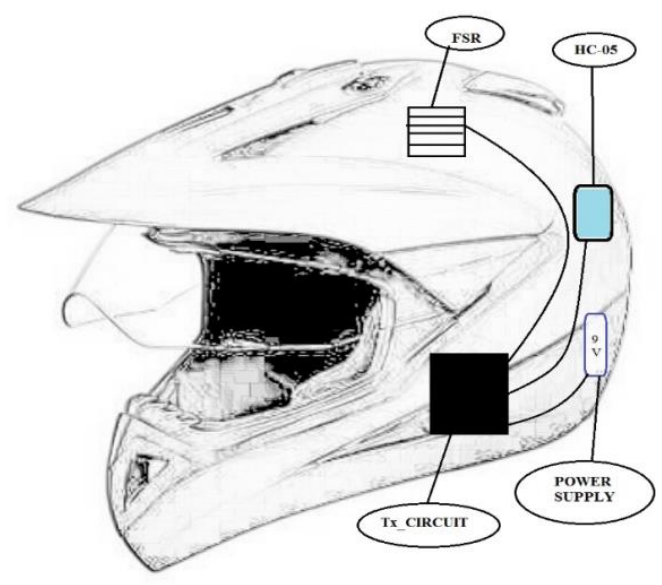

Fig.11. Circuit board in the helmet.

\section{(E) Installing the designed circuit board in the vehicle}

According to this research device the circuitry should installed in a vehicle is Receiver circuit designed by an atmega16 microcontroller with the internal supply of 5VDC given by an adaptor from the vehicle battery. In this device we used Bluetooth module to receive the data, it is in the mode of slave. The $16^{*} 2 \mathrm{LCD}$ is interfaced to one of the port of the microcontroller to display the current statues. Microcontroller initializes a pin as output to the relay with the help of transistor.

\section{Connected Modules With Working Principles}

(A) Working of Receiving Device

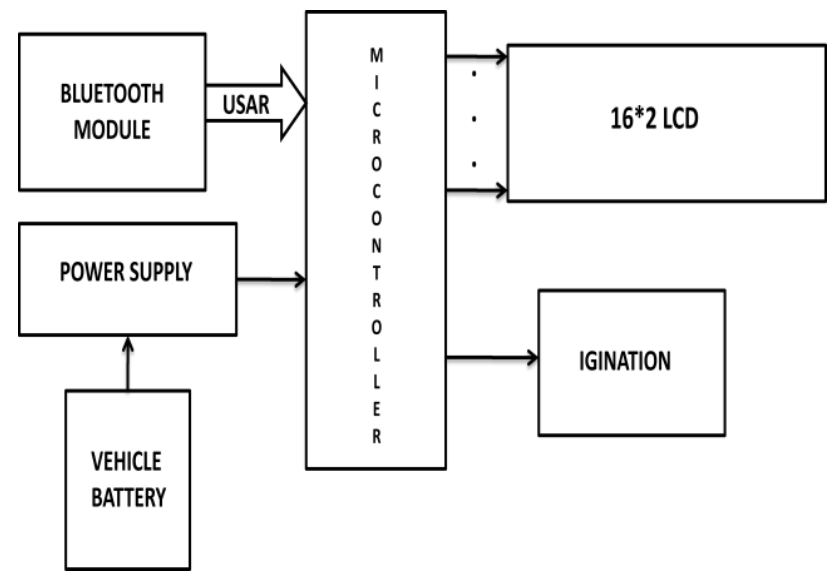

Fig.12. Connectivity of Receiver Block Diagram 
In this research work the data which is transmitted by the master module is received by slave module which is present in vehicle. The slave Bluetooth module forwards the data to the microcontroller. For receiving the data the controller should enable the receiver mode. As per the data received is "HIGH" and "LOW" therefore if it receives high then the display monitors the statues "HELMET CONNECTED" and the relay works as a closed switch by this switching the ignition turns "ON". At this condition the vehicle is ready to start and can move on. Or else if it receives low then the display monitors the statues "HELMET DISCONNECTED" and the relay works as an open switch by this switching the ignition turns "OFF". At this condition the vehicle is not ready to start. To operate the relay we used transistor as a switch condition. This condition is applicable when to operate high voltage device with low control signal. The supply is given from the vehicle battery by using voltage adapter of output $5 \mathrm{~V} \mathrm{dc}$ with $2 \mathrm{Amp}$. Here, the $16 * 2 \mathrm{LCD}$ is connected in 4-bit mode.

(B) Working of Transmitted Device

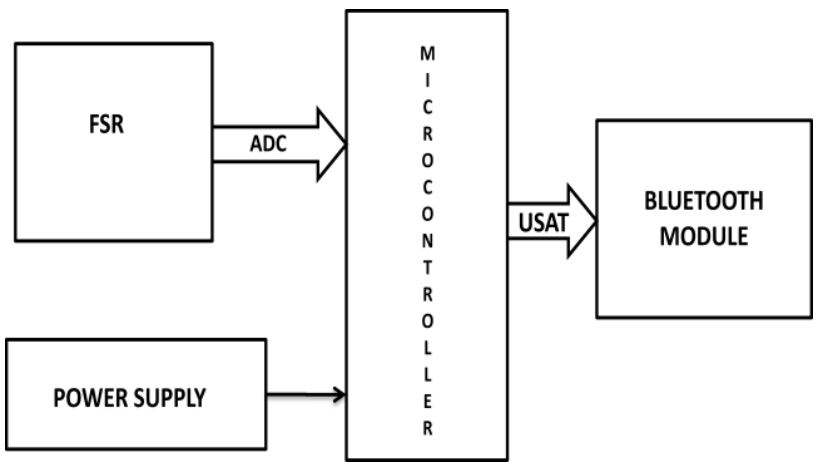

Fig.13. Connectivity of Transmitter Block Diagram

In this research work we considered that the output of the Force Sensing Resistor (FSR) gives the output signal according to the force is applied on it. The result of this FSR is shown in the above tabular Table.1 and graphical form Fig.4. The FSR output is in analog form which is necessary to convert into digital form. Due to this reason we enabled ADC in the microcontroller at PORTA.

The master module acts as a transmitter in this device. To transmit the data we need to enable the Transmit mode from the USART of the microcontroller. The condition to communicate the master module and the microcontroller is to cross connect the pins such as $\mathrm{Tx}$ pin of Microcontroller to the Rx pin of Master Bluetooth module. Finally, we applies a logic in the controller i.e. if the FSR output is greater than the reference voltage (Vreff) then it transmits "HIGH" or else if the reference voltage is less then it transmits "LOW". The total circuitry works on $5 \mathrm{~V}$ dc supply it has been provided by a battery source.

\section{FlowChart AND REPRESENTATION}

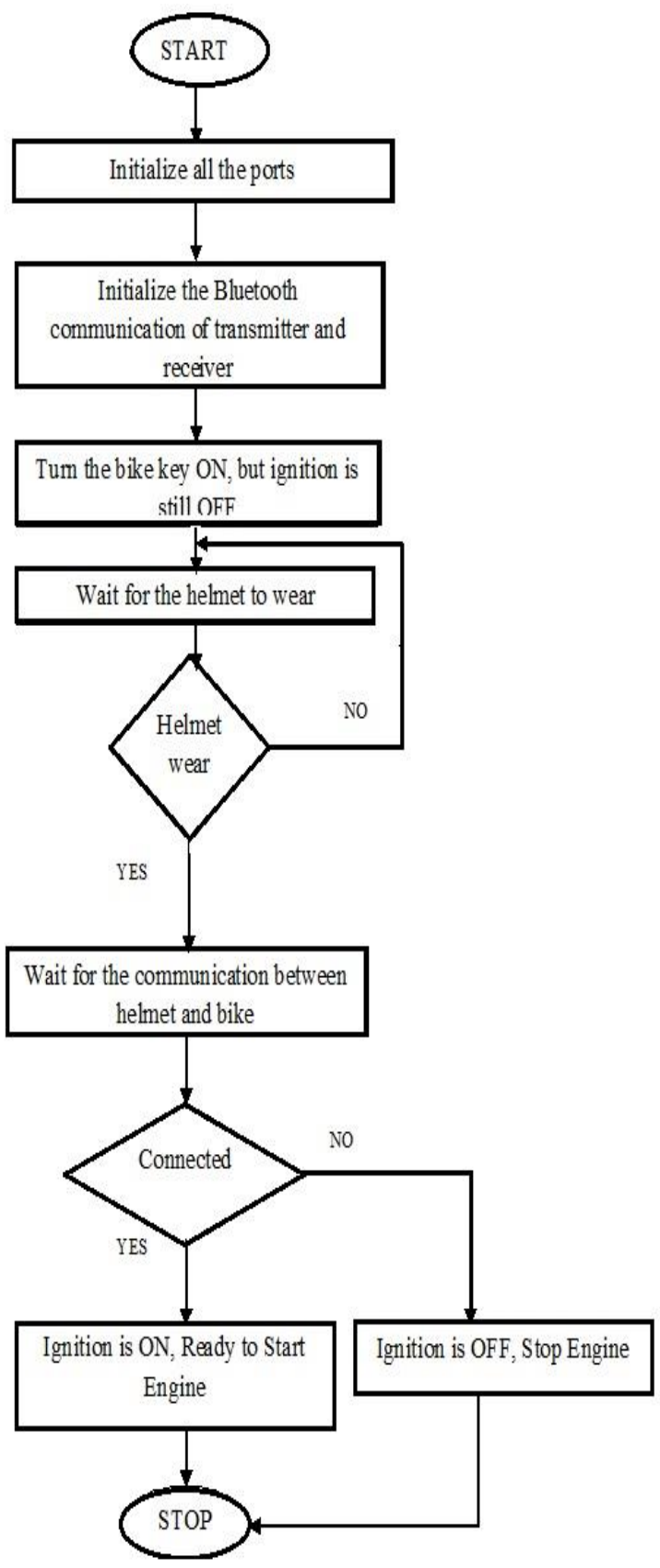

Fig.14. Flowchart and representation of the innovation.

By this research we are implementing this device for the safety of the driver. In this research work we firstly, Initialization of all the ports and Bluetooth modules are ready to communicate. The driver should key on the ignition. Now, the driver has to wear the helmet to step on next otherwise it waits until the helmet to wear. Then the helmet and the bike have to communicate, if helmet is connected the ignition turns "ON". Now the engine is ready to start. Else, if helmet is disconnected the ignition turns "OFF". Now the engine is not in a state to start. Now, we can have a safe journey. 


\section{INNOVATED HARDWARE}

The proposed Research work is implemented in real time. The actual interface is shown in following Fig.15 and Fig.16. In the form of screenshot interfaced with proposed necessity of helmet idea. The proposed work is found accurate and kept under testing of 9 days up to 495 kilometers.

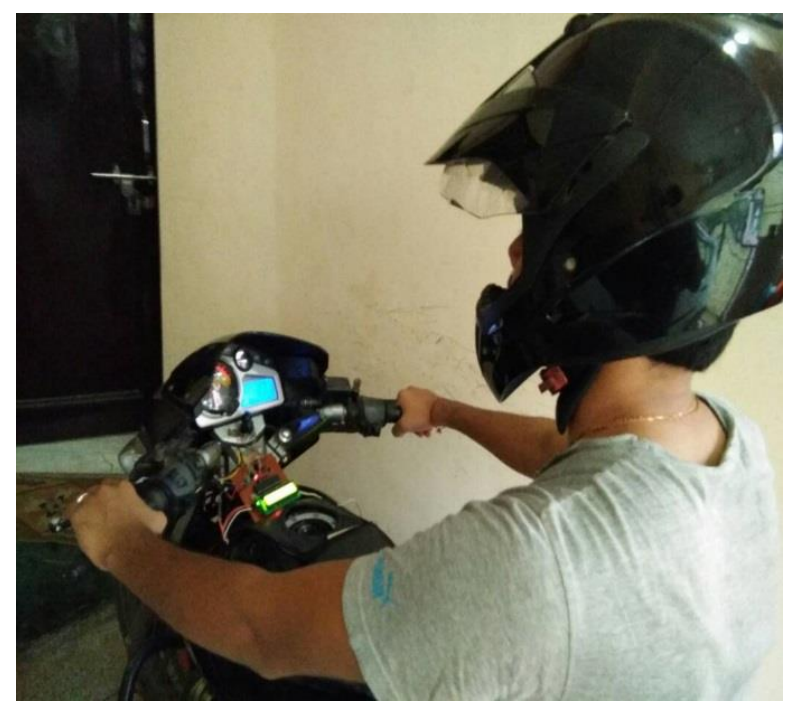

Fig.15. Innovated picture of helmet is connected.

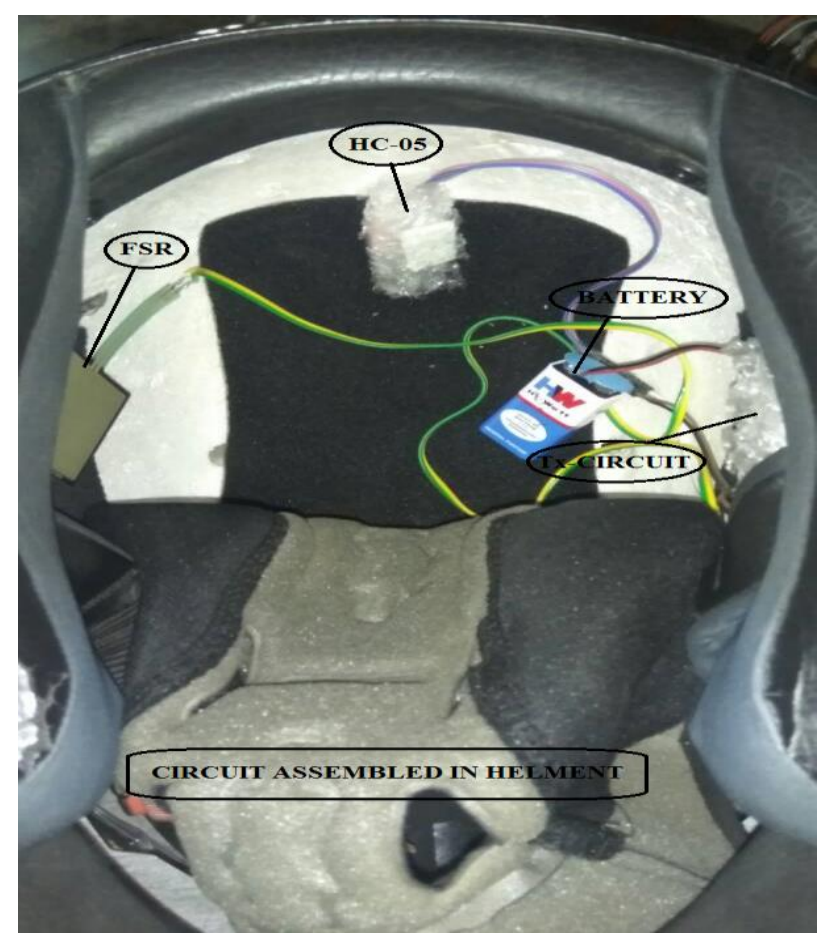

Fig.16. Circuitry setup in the helmet.

\section{FUTURE SCOPE}

1. This proposed project can be implemented in BS-IV vehicles.
2. Further we can make helmet is compulsory (without helmet we can't ride the bike).

3. Protect the driver life in accidents.

4. Decrease the death rate in road accidents.

\section{CONCLUSION}

The proposed Smart Helmet is tested and implemented in helmet and vehicle successfully. This work can also implement in the other application domains. The project has showed that the bike ignition will start if the helmet is worn. So, it will automatically decrease the effect from accident and it can avoid bike from being stolen. Executing the wireless system which Bluetooth Module to send signal from helmet device to the bike device. This wireless connection is better than wired link.

\section{ACKNOWLEDGEMENT}

The authors of this paper would resemble to expressive great appreciation to ITM University Gwalior.

\section{REFERENCES}

[1] Smart Helmet with Sensors for Accident Prevention Mohd Khairul Afiq Mohd Rasli, Nina Korlina Madzhi, Juliana Johari Faculty of Electrical Engineering University Tecnology MARA40450 Shah Alam Selangor, MALAYSIAjulia893@salam.uitm.edu.my

[2] A Smart Safety Helmet using IMU and EEG sensors for worker fatigue detection Ping Li, Ramy Meziane, Martin J.-D. Otis, Hassan Ezzaidi, REPARTI Center, University of Quebec at Chicoutimi Chicoutimi, Canada Email: Martin_Otis@uqac.ca Philippe Cardou REPARTI Center, Laval University Quebec, Canada Email: pcardou@gmc.ulaval.ca)

[3] Harish Chandra Mohanta, Rajat Kumar Mahapatra and Jyotirmayee Muduli(2014)", Anti-Theft Mechanism System with Accidental Avoidance and Cabin Safety System for Automobiles", International Refereed Journal of Engineering and Science (IRJES), Vol. 3, No. 4, pp. $56-62$.

[4] Laxmi R, Saritha B, Priyadharshini B,Deepeka S and Vijay J (2011), "Drunken Drive Protection System", International Journal of Scientific \& Engineering Research, Vol. 2, No. 12, ISSN: 2229-5518.

[5] Boutigny, Pierre-Henri; Nguyen, Huy Anh; Raoulx, Denis; , "1GHz Analog Comparator and Switch Matrix for 8-Channel Analog Data Acquisition System," SolidState Circuits Conference, 1988. ESSCIRC '88. Fourteenth European, vol., no., pp.106-109, 21-23 Sept. 1988

[6] Hart, B.L.; , "Precision voltage-divider circuit," Electronics Letters ,vol.7, no.23, pp.679-680, November 181971

[7] Jianyun Ni; Jing Luo; "Microcontroller-based engineering education innovation," Educational and Information Technology (ICEIT), 2010 International Conference on , vol.3, no., pp.V3-109-V3-112, 17-19 Sept. 2010

[8] Ian, Paul. "Wi-Fi Direct vs. Bluetooth 4.0: A Battle for Supremacy". PC World. Retrieved 27 December 2013.

[9] F.L. Lewis. "Wireless Sensor Networks." Smart Environments: Technologies, Protocols, and Applications, ed. D.J. Cook and S.K. Das, John Wiley, New York, 2004 Automation and robotics research institute. 26 Oct. 2013 
[10] Yvonne Toft; Geoff Dell; Karen K Klockner; Allison Hutton (April 2012). "Models of Causation: Safety". In HaSPA (Health and Safety Professionals Alliance). OHS Body of Knowledge(PDF). Safety Institute of Australia Ltd. ISBN 978-0-9808743-1-0.Wigmore, I. (June 2014). "Internet of Things (IoT)". TechTarget.

[11] Seelam Vasavi Sai Viswanada Prabhu Deva Kumar, Shyam Akashe "Implementation of GSM Based Security System with IOT Applications" I. J. Computer Network and Information Security, 2017, 6, 13-20.

[12] Sultan A. Alhumrani and Rizwan J. Qureshi "Novel Approach to Solve Resource Constrained Project Scheduling Problem (RCPSP)" I.J. Modern Education and Computer Science, 2016, 9, 60-68.

[13] Yadwinder Singh, Lakhwinder Kaur "Obstacle Detection Techniques in Outdoor Environment: Process, Study and Analysis" I.J. Image, Graphics and Signal Processing, 2017, 5, 35-53.

[14] Ashraf Adamu Ahmad, Aminu Inuwa Kuta, Abdulmumini Zubairu Loko "Analysis of Abdominal ECG Signal for Fetal Heart Rate Estimation Using Adaptive Filtering Technique" I.J. Image, Graphics and Signal Processing, 2017, 2, 19-26.

[15] Olutayo V.A, Eludire A.A "Traffic Accident Analysis Using Decision Trees and Neural Networks" I.J. Information Technology and Computer Science, 2014, 02, 22-28.

\section{Authors' Profiles}

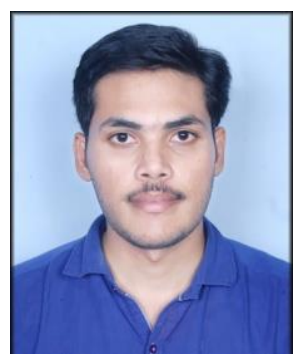

Seelam Vasavi Sai Viswanada Prabhu Deva Kumar born in "Chintalapudi" a city in Andhra Pradesh, India on $15^{\text {th }}$ June $1996 . \mathrm{He}$ is pursuing B.Tech in Electronics \& Communication Engineering from Institute of Technology \& Management University (ITMU), Gwalior in 2014-2018 and area of interest in LED Fabrication and Designing, Embedded Systems, IoT (Internet of Things), Low Power VLSI Design, Modelling, and CMOS based memory design, Circuits for future VLSI Technology, Digital Design \& FPGA Implementation. He worked as an Intern in Fuzinix Infotech Pvt. Ltd. and SION Semiconductors Pvt. Ltd. Seelam Vasavi Sai Viswanada Prabhu Deva Kumar is authored published few research papers in peer reviewed international journals. He is an Editorial Member in International Journal of Information Technology and Computer Science (IJOIT).

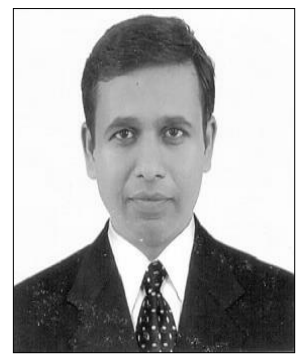

Dr. Shyam Akashe born in "Achalpur" a city in Maharashtra, India on $22^{\text {nd }}$ May 1976. He did M.Tech in Electronics \& Communication Engineering from Rajiv Gandhi Proudyogiki Vishwavidyalaya (RGPV), Bhopal in 2006 and Ph.D Thapar University, Patiala (previously Thapar Institute of Engineering and Technology), Punjab in 2013. Dr. Akashe worked as Assistant Professor at Institute of Technology \& Management (ITM) Gwalior. Currently, he is working as Professor and Post-graduation Coordinator, Electronics \& Communication Engineering department at ITM University Gwalior. Dr. Akashe is authored/co-authored more than 200 research papers in peer reviewed international/national journals and conferences. He has also published 5 patent, 2 copyright, 2 books and 1 chapter. His biography published in Marquis's Who's Who in Engineering Field, USA awarded by Marquis, 2015.

His areas of research are Low Power VLSI Design, Modeling, FinFET based memory design, Circuits for future VLSI Technology, Digital Design and FPGA implementation. He is life member of the Institution of Engineers (IE), Life Member of the Indian Society for Technical Education (IETE), Life Member of the Indian Society for Technical Education (ISTE) and Life Member of the Instrumentation Society of India (ISOI), also he is member of VLSI Society of India (VSI). Dr. Akashe is editorial board member of the IEEE African Journal of Computing \& ICTS (IEEE Nigeria). He is also a reviewer for IEEE Transaction on VLSI Systems, IEEE Transactions on Nanotechnology, International Journal of Electronics (Taylor and Francis), Microelectronics Journal (Elsevier).

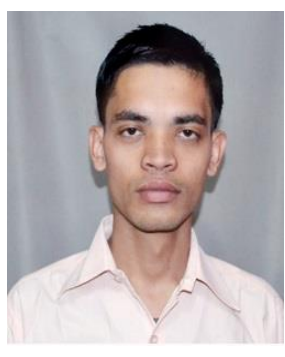

Vikram Kumar, born in "Muzaffarpur" a city in Bihar, India on $14^{\text {th }}$ October 1996. He is pursuing B.Tech in Electronics \& Communication Engineering from Institute of Technology \& Management University (ITMU), Gwalior in 2014-2018 and area of interest in Embedded Systems, IoT and Networking.

How to cite this paper: Seelam Vasavi Sai Viswanada Prabhu Deva Kumar, Shyam Akashe, Vikram Kumar," Advanced Control of Switching Ignition by Smart Helmet", International Journal of Image, Graphics and Signal Processing(IJIGSP), Vol.10, No.2, pp. 34-42, 2018.DOI: 10.5815/ijigsp.2018.02.04 